\title{
Ants Visiting the Post-Floral Secretions of Pericarpial Nectaries in Palicourea rigida (Rubiaceae) Provide Protection Against Leaf Herbivores But Not Against Seed Parasites
}

\author{
K Del-Claro ${ }^{1}$, R Guillermo-Ferreira ${ }^{2}$, EM Almeida ${ }^{3}$, H ZARDinI $^{1}$, HM TorezAn-SilingardI ${ }^{1}$ \\ 1 - Universidade Federal de Uberlândia, Uberlândia, Minas Gerais, Brazil. \\ 2 - Universidade de São Paulo, Ribeirão Preto, São Paulo, Brazil. \\ 3 - Empresa de Pesquisa Energética, Superintendência de Meio Ambiente, Rio de Janeiro, Rio de Janeiro, Brazil.
}

\section{Article History \\ Edited by \\ Gilberto M M Santos, UEFS, Brazil \\ Received 02 May 2013 \\ Initial acceptance 30 May 2013 \\ Final acceptance 06 July 2013}

\section{Key words}

Mutualism, ant-plant interactions, parasitism, seed predation, herbivory

\section{Corresponding author}

Kleber Del-Claro

Instituto de Biologia, L.E.C.I.

Universidade Federal de Uberlândia

Uberlândia, MG, Brazil, 38400-902

E-Mail: delclaro@ufu.br

\begin{abstract}
Pericarpial nectaries (PNs) have frequently been treated in the literature as extrafloral nectaries (EFNs). This treatment is partly justified by their morphological and functional similarities in attracting bodyguard ants to protect the plant against herbivores. Palicourea rigida is a common Neotropical savanna treelet with tubular yellow flowers that are pollinated by hummingbirds. After pollination, the corolla falls, but the sepal ring remains and keeps the nectaries active over the ovarium throughout fruit development stages. Using a standard ant-exclusion experiment, we tested whether these PNs attract ants to protect the developing fruits against seed parasites and the leaves against chewing herbivores. We analyzed the differences between the initial and final leaf area. Before full fruits maturity, they were collected and taken to the laboratory for weighing and to observe wasp emergence. The number of wasps per fruit and per plant was recorded. The results showed that after pollination, the floral nectaries of $P$. rigida act as EFNs, attracting visiting ants. Ant-tended plants lost significantly less leaf area and had heavier fruits than untended plants. However, the ants did not protect the fruits against seed-parasitic wasps. In P. rigida, the post-floral secretions of PNs play the same role as EFNs, and the ant-plant mutualism is context-dependent based on the type of herbivore and the plant tissue consumed.
\end{abstract}

\section{Introduction}

In some plant species, floral nectaries may remain active after pollination, attracting ants that defend the plants against herbivores. Thus, these nectaries act as extrafloral nectaries (EFNs) and are sometimes called extra-nuptial nectaries (ENNs; Delpino, 1886), postfloral nectaries (Daumann, 1932), or more recently, pericarpial nectaries (PNs; Schmid, 1988). These glands have frequently been treated in the literature as EFNs. This treatment is partly justified by their morphological and functional similarities (see Paiva, 2009 for a review). Extrafloral nectaries are secretory glands that are not directly involved in pollination (Fiala \& Machwistz, 1991) and may occur in any vegetative or reproductive plant part (Keeler, 1989). EFNs have been reported in 3941 species in $21 \%$ of vascular-plant families, representing a widespread evolutionary trait that has evolved several times (Weber \& Keeler, 2012). Recent evidence suggests that EFNs are homologous within eudicots, sharing common genetic controls and homology with floral nectaries (Lee et al., 2005; Weber \& Keeler, 2012).

A wide variety of predatory taxa exhibit mutualistic interactions with plants, providing protection against herbivores in exchange for nectar and thus complementing their diets by visiting plants with EFNs for their sugary secretions (Byk \& Del-Claro, 2011) while enhancing plant fitness (Rosumek et al., 2009; Nascimento \& Del-Claro, 2010; Romero \& Koricheva, 2011). For example, ants (Oliveira \& Brandão, 1991), spiders (Ruhren \& Handel, 1999; Nahas et al., 2012) and Reduviidae (Guillermo-Ferreira et al., 2012) have been observed feeding on EFNs and attacking approaching herbivores. 
Such arthropod-plant interactions may represent a strong force driving the evolution of EFNs (e.g. Del-Claro \& Oliveira, 1993). However, because herbivory may affect all parts of the plant, the effects of carnivores on plant fitness may be context-dependent based on the type of tissue consumed by the herbivores (Marquis, 1992). For example, ants and jumping spiders protect the vegetative parts of Chamaecrista nictitans (Caesalpiniaceae), thus increasing fruit and seed production, but these insects do not deter seed predation (Ruhren \& Handel, 1999; Ruhren, 2003; see also Nahas et al., 2012).

The continuous post-floral secretion (following pollination) by PNs and the adaptive significance of this trait remain underexplored; only one study has suggested that PNs function as true EFNs in attracting ants to protect the seeds against herbivores (Keeler, 1981). However, it is not clear whether such protection extends to the vegetative components of the plant because ants generally visit the nectaries on fruits.

The treelet Palicourea rigida Kunth. (Rubiaceae) is a common shrub in the Brazilian savanna (Cerrado). The genus Palicourea is Neotropical and encompasses 200 species of small trees and shrubs (Taylor, 1993). These species are distinguished by certain characteristics of their yellow-red tubeshaped corollas, which exhibit adaptations for hummingbird pollination (Taylor, 1996). The fruits are fleshy, purple and ornithochorous (Wütherich et al., 2001). In P. rigida, after the corolla falls, the sepal ring remains active and produces nectar over the fruits throughout their development (Figure 1). The fruits commonly show marks of the exit holes made by seed-parasitic wasps that develop inside the growing seeds, as occurs in P. salicifolia (Wesselingh et al., 1999).

The aim of this study was to test the hypothesis that after pollination, the floral nectaries of $P$. rigida can be considered true EFNs. If so, ants visiting these nectaries should reduce plant herbivory (leaf-area loss) and parasitic-wasp attacks on the fruits.

\section{Materials and Methods}

This study was conducted in the Cerrado area of the "Clube de Caça e Pesca Itororó de Uberlândia" Ecological Reserve (CCPIU; 15 $57^{\circ}$ 'S, 48 $8^{\circ} 12^{\prime} \mathrm{W}$; 640 ha) (for additional details about the study area, see Réu \& Del-Claro, 2005). Field experiments were performed during the reproductive season of P. rigida in 1996, 2001 and 2005. By the flip of a coin, we designated tagged shrubs as control plants (with unrestricted ant access; $\mathrm{N}=20$ in $1996, \mathrm{~N}=25$ in 2001, $\mathrm{N}=22$ in 2005) or treatment plants (with ants excluded by applying the Tanglefoot ${ }^{\circledR}$ resin on the main plant stem; $\mathrm{N}=20$ in 1996, $\mathrm{N}=24$ in 2001, $\mathrm{N}=22$ in 2005).

Between October 1996 and February 1997, we collected and weighed the fruits of the control and treatment groups. Between November 2001 and April 2002, we col-

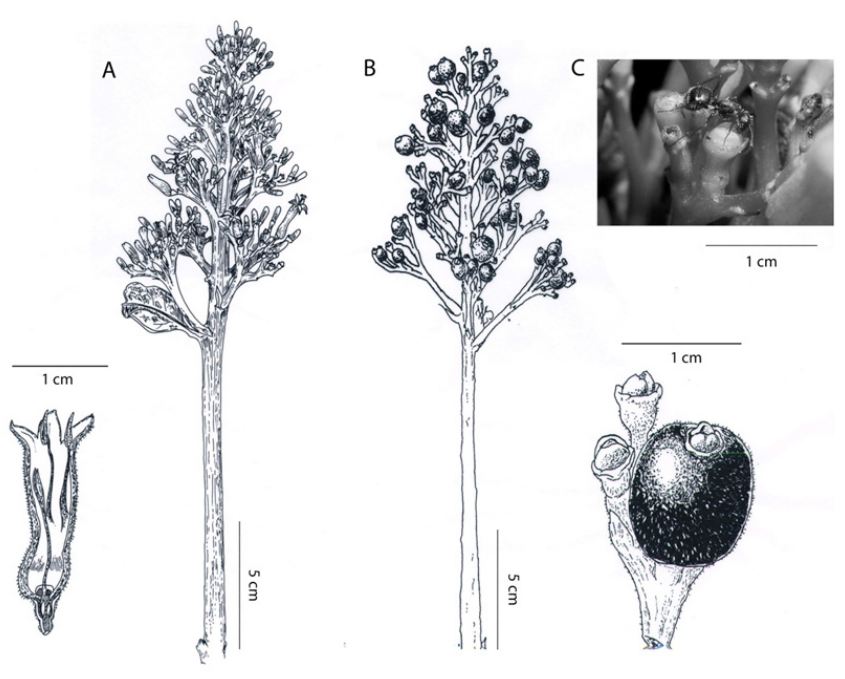

Figure 1. Inflorescence of the treelet Palicourea rigida. (A) Longitudinal section (in detail) of a flower and developing fruits on the same stem. (B) After pollination, the corolla falls, and the pericarpial nectaries remain active. (C) Ants (Camponotus crassus Mayr, 1962) feed on the post-floral secretions.

lected data on leaf herbivory by measuring the leaf-area loss (damage by chewing insects - the three most apical and full expanded leaves of each plant) at the beginning and end of the experiment (sensu Moreira \& Del-Claro, 2005). Between November 2005 and June 2006, we investigated the presence of seed-parasitic wasps by collecting the developing fruits and keeping them in plastic containers for 30 days until the wasps emerged from the pupae. The fruits were collected before full maturity to avoid interference by frugivorous birds. At the end of the study in 2005, 21 control and 18 treatment plants remained because 5 plants died during the experiment.

To determine whether the ants protected the fruits against seed parasites, we calculated the infestation rates as follows: (i) the number of infested plants divided by the total number of plants and (ii) the number of wasps per fruit and per plant in the treatment and control groups. To assess the correlation between fruit production and infestation level, we used the Spearman coefficient.

The data on wasp-infestation rates, leaf herbivory and fruit weight were compared between groups using the MannWhitney (U test). The numbers of infested plants in the control and treatment groups were compared using Fisher's exact test. All tests were performed using the software Statistica $10 \AA$. Data under parenthesis represent median \pm standard deviation.

\section{Results}

The results showed that leaf damage increased significantly in ant-excluded plants (initial herbivory $=16.79$ $\pm 14.10 \%$; final herbivory $=25.73 \pm 16.52 \%$; $U=47.50$, 
$\mathrm{p}<0.05)$, while the initial $(14.65 \pm 12.17 \%)$ and final $(23.54$ $\pm 20.62 \%$ ) leaf-area loss were not significantly different in plants with unrestricted ant access $(\mathrm{U}=143.00 \mathrm{p}>0.05$; Figure 2). Furthermore, the fruits were heavier in the control group $(0.203 \pm 0.114 \mathrm{~g}, \mathrm{~N}=360$ fruits $)$ than in the treatment group $(0.144 \pm 0.092 \mathrm{~g}, \mathrm{~N}=340$ fruits $)(\mathrm{U}=52.50, \mathrm{p}<0.05)$. However, there was no difference in fruit formation between plants with $(0.32 \pm 0.17)$ and without ants $(0.36 \pm 0.17)$. In the three years of experiments the main ant species observed on plants were: Camponotus crassus Mayr, 1862; Cephalotes pusillus Klug, 1824 and Pseudomyrmex gracilis Frabicius, 1804.

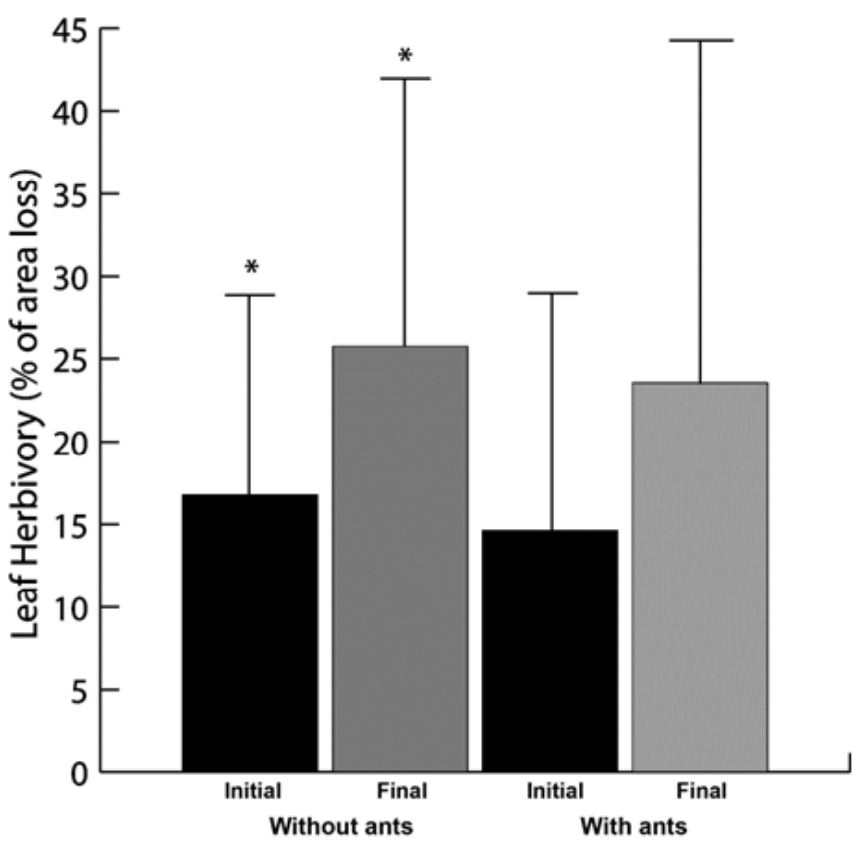

Figure 2. Leaf-area loss in Palicourea rigida (Rubiaceae) in antexclusion experiments and with pericarpial nectaries visited by ants. *, $\mathrm{P}<0.05$ (Mann-Whitney U test).

Parasitic wasps, two Braconidae, one Pteromalidae and one Eulophidae of Galeopsomyia genus (Tetrastichinae) were found in $44 \%(8 / 18)$ of the plants in the treatment group and $62 \%(13 / 21)$ of the plants in the control group. Wasp infestation did not differ significantly between groups (Fisher's exact test, $p=0.13$ ). The mean number of wasps per fruit did not differ between the control $(0.14 \pm 0.17)$ and treatment $(0.07 \pm 0.11)$ groups $(\mathrm{U}=145.00, \mathrm{p}=0.19)$, and the mean number of wasps per plant did not differ between plants with $(12.87 \pm 9.31)$ and without ants $(8.50 \pm 8.36)(\mathrm{U}=141.00, \mathrm{p}$ $=0.18$ ). In addition, the number of wasps recovered per plant increased with the number of fruits per plant $(\mathrm{r}=0.54, \mathrm{~N}=$ $21, \mathrm{p}<0.02$; Figure 3).

\section{Discussion}

The pericarpial nectaries of $P$. rigida attract ants that feed on the post-floral secretions and prey on or chase away chewing herbivores, significantly reducing leaf-area loss.
Thus, the PNs act as true EFNs, confirming our primary hypothesis.

However, our results also show that the ants do not provide any protection against seed-parasitic wasps. These wasps may affect plant fitness by reducing the number of viable seeds (Huffman 2002), resulting in losses greater than $80 \%$ in some plant species (Andersen 1989). The relationship between the number of fruits and the number of wasps per plant may explain these results because a large infructescence may represent a more heterogeneous and complex structure to be explored and defended by ants, enabling the small wasps to parasitize the fruits without notice (e.g., TorezanSilingardi, 2011; Alves-Silva et al., 2012).

Hence, contrary to prior assumptions that a nectary on the fruit must attract ants to protect the fruit, this study suggests that the PNs of P. rigida most likely did not evolve to play a role in fruit or seed protection but to reward ants with nectar in exchange for protecting the vegetative parts of the plant. Our results support this hypothesis because the ants protected the leaves against herbivory, thus indirectly increasing fruit weight. Leaf-area reduction due to herbivory may negatively affect fruit and seed weight (Thalmann et al., 2003) by reducing the resources available for fruit production (Stephenson, 1980). By decreasing fruit weight, herbivory has a crucial negative impact on future generations because seed weight influences seedling growth, germination and mortality (Fenner, 2006; Rees \& Venable, 2007).

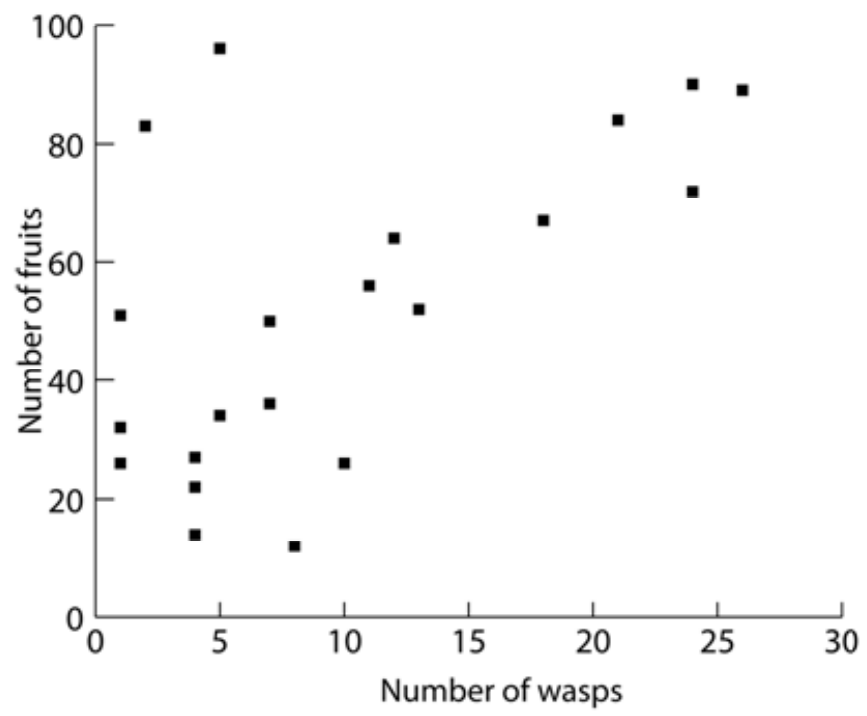

Figure 3. Fruit-parasitoid wasp infestation level is positively correlated with fruit abundance in Palicourea rigida (Rubiaceae) (Spearman correlation: $\mathrm{r}=0.54, \mathrm{~N}=21, \mathrm{p}<0.02$ ).

Numerous studies have shown that ants protect EFNbearing plants against herbivores, thus increasing their reproductive success, in various parts of the world (e.g. Keeler, 1989; Koptur, 1992). However, the majority of published data refer to plant species that bear EFNs on their vegeta- 
tive parts (see Rico-Gray \& Oliveira, 2007 for review). The present study provides data for a species that bears EFNs on its fruits. Despite being borne on the fruits, these EFNs are responsible for the plant's anti-herbivory strategy, attracting ants that prevent leaf herbivory.

Similar to other studies, our data show that the defensive function (or lack thereof) of nectaries in this type of ant-plant mutualism depends upon the context, especially upon the type of herbivore, the tissue consumed, the visiting predators and phylogenetic inertia (O'Dowd \& Catchpole, 1983; Marquis, 1992; Rashbrook et al., 1992; Cuautle \& Rico-Gray, 2003; Jones \& Callaway, 2007; Byk \& Del-Claro 2010; Nogueira et al., 2011; Weber \& Keeler, 2012).

In conclusion, our data show that in $P$. rigida, the nectaries located on the fruits attract ants, which protect the plant against leaf-chewing herbivores. However, the prediction that the PNs play a role in fruit and seed defense was not supported. Along with Keeler (1981), this study provides information about the adaptive significance and evolution of PNs and EFNs. Considering the few species of Rubiaceae that are known to possess EFNs and the benefits that ants may provide to fruit production, we suggest that the PNs in this group can be considered true EFNs selected as a defensive strategy through ant attraction.

\section{Acknowledgements}

We thank CNPq for providing financial support (KDC 301248; KDC and HMTS 476074, 472046, 473055). We thank Christer Hansson and John La Salle for identifying the wasps. We also thank two anonymous reviewers for valuable comments that improved this article.

\section{References}

Alves-Silva, E., Barônio, G.J., Torezan-Silingardi, H.M. \& Del-Claro, K. (2012). Foraging behavior of Brachygastra lecheguana (Hymenoptera: Vespidae) on Banisteriopsis malifolia (Malpighiaceae): Extrafloral nectar consumption and herbivore predation in a tending ant system. Entomol. Sci., 16:162-169.

Andersen, A.N. (1989). How important is seed predation to recruitment in stable populations of long-lived perennials? Oecologia, 81:310-315.

Byk, J. \& Del-Claro, K. (2010). Nectar- and pollen-gathering Cephalotes ants provide no protection against herbivory: a new manipulative experiment to test ant protective capabilities. Acta Ethol., 13: 33-38.

Byk, J., Del-Claro, K. (2011). Ant-plant interaction in the Neotropical savanna: direct beneficial effects of extrafloral nectar on ant colony fitness. Popul. Ecol., 53: 327-332.

Chase, J.M., Abrams, P. A., Grover, J. P., Diehl, S., Chesson, P., Holt, R. D., Richards, S. A., Nisbet, R. M. \& Case, T.J. (2002). The interaction between predation and competition : a review and synthesis. Ecol. Lett., 5: 302-315.

Del-Claro, K. \& Oliveira, P.S. (1993). Ant-Homoptera Interaction: do Alternative Sugar Source Distract Tending Ants? Oikos, 68: 202-206.

Delpino, F. (1886). Funzione mirmecofila nel Regno vegetale. Memorie della R. Accademia delle Scienze dell'Istituto di Bologna Ser IV, 7: 215-323.

Fiala, B. \& Machwistz, U. (1991). Extrafloral nectaries in the genus Macaranga (Euphorbiaceae) in Malaysia: comparative studies of their possible significance as predispositions for myrmecophytism. Biol. J. Linn. Soc., 44: 287:305.

Fowler, S.V. \& Macgarvin, M. (1985). The Impact of Hairy Wood Ants, Formica lugubris, on the Guild Structure of Herbivorous Insects on Birch: Betula pubescens. J. Anim. Ecol., 54: $847-855$.

Huffman, D.W. (2002). A seed chalcid (Eurytoma squamosa Bugbee) parasitizes seeds of Fendler ceanothus (Ceanothus fendleri Gray) in a ponderosa pine forest of Arizona. Western North Am. Nat., 62: 474-478.

Keeler, K.H. (1981). Function of Mentzelia nuda (Loasaceae) postfloral nectaries in seed defense. Am. J. Bot., 68: 295299.

Keeler, K.H. (1989). Ant-plant interactions, p. 207-242. In W.G. Abrahamson. Plant-animal interactions. McGraw-Hill, New York.

Koptur, S. (1992). Extrafloral nectaries-mediated interactions between insects and plants. Insect-Plant interactions, vol. 4 (ed. E. Bernays), pp. 81-129. CRC Press, Boca Raton.

Marquis, R.J. (1992). Selective impact of herbivores. Plant Resistance to Herbivores and Pathogens: Ecology, Evolution, and Genetics (eds R. S. Fritz \& E. L. Simms), pp. 301-325. The University of Chicago Press, Chicago.

Moreira, V.S.S. \& Del-Claro, K. (2005). The outcomes of an ant-threehopper association on Solanum lycocarpum St. Hil: increased membracid fecundity and reduced damage by chewing herbivores. Neotrop. Entomol., 34: 881-887.

Morellato, L.P.C. \& Oliveira, P.S. (1994). Extrafloral nectaries in the tropical tree Guarea macrophylla (Meliaceae). Can. J. Bot., 72: 157 - 160.

Nahas, L., Gonzaga, M.O. \& Del-Claro, K. (2012). Emergent Impacts of Ant and Spider Interactions: Herbivory Reduction in a Tropical Savanna Tree. Biotropica, 44: 498-505.

Nascimento, E.A. \& Del-Claro, K. (2010). Ant visitation to extrafloral nectaries decreases herbivory and increases fruit set in Chamaecrista debilis (Fabaceae) in a Neotropical savanna. Flora, 205: 754-756.

O'Dowd, D.J. \& Catchpole, E.A. (1983). Ants and extrafloral nectaries: no evidence for plant protection in Helichrysum 
spp. - ant interactions. Oecologia, 59:191-200.

Oliveira, P.S. \& Brandão, C.R.F. (1991). The ant community associated with extrafloral nectaries in Brazilian cerrados. Ant-Plant Interactions (eds D. F. Cutler \& C. R. Huxley), pp. 198-212. Oxford University Press, Oxford.

Paiva, E.A.S. (2009). Ultrastructure and post-floral secretion of the pericarpial nectaries of Erythrina speciosa (Fabaceae). Ann. Bot., 104: 937-944.

Proulx, M. \& Mazumder, A. (1998). Reversals of grazing impact on plant species richness in nutrient-poor vs. nutrient-rich ecosystems. Ecology, 79: 2581-2592.

Rashbrook, V.K., Compton, S.G. \& Lawton, J.H. (1992). Antherbivore interactions: reasons for the absence of benefits to a fern with foliar nectaries. Ecology, 73: 2167-2174.

Réu, W.F. \& Del-Claro, K. (2005). Natural History and Biology of Chlamisus minax Lacordaire (Chrysomelidae: Chlamisinae). Neotrop. Entomol., 34: 357-362.

Rico-Gray, V. \& Oliveira, P. S. (2007). The ecology and evolution of ant-plant interactions. Chicago: The University of Chicago Press.

Rico-Gray, V. (1993). Use of plant-derived food resources by ants in the dry tropical lowlands of coastal Veracruz, Mexico. Biotropica, 25: 301-315.
Ruhren, S. (2003). Seed predators are undeterred by nectarfeeding ants on Chamaecrista (Caesalpinaceae). Plant Ecol., 166: 189-198.

Spiller, D.A. \& Schoener, T.W. (1988). An experimental study of the effect of lizards on web-spider communities. Ecol. Monogr., 58: 57-77.

Taylor, C.M. (1993). Revision of Palicourea (Rubiaceae: Psychotrieae) in the West Indies. Moscosoa, 7: 201-241.

Taylor, C.M. (1996). Overview of the Psychotrieae (Rubiaceae) in the Neotropics. Opera Bot. Belg., 7: 261-270.

Torezan-Silingardi, H.M. (2011). Predatory behavior of Pachodynerus brevithorax (Hymenoptera: Vespidae, Eumeninae) on endophytic herbivore beetles in the Brazilian tropical savanna. Sociobiology, 57: 181-190.

Wesselingh, R.A., Witteveldt, M., Morissette, J. \& den-Nijs, H.C.M. (1999). Reproductive Ecology of Understory Species in a Tropical Montane Forest in Costa Rica. Biotropica, 31: 637-645.

Wolda, H. (1983). Diversity, diversity indices and tropical cockroaches. Oecologia, 58: 290-98.

Wutherich, D., Azoca, A., Garcia-Nunez, C. \& Silva, J.F. (2001). Seed dispersal in Palicourea rigida, a common treelet species from Neotropical Savannas. J. Trop. Ecol., 17: 449-458. 